\title{
Leading the creativity
}

\author{
Simona Sofia Duicu, ${ }^{1, *}$ \\ ${ }^{1}$ Transilvania University of Brasov, Department of Manufacturing Engineering, Mihai Viteazu No. 5, \\ Brasov, Romania
}

\begin{abstract}
The paper presents some consideration about creative learning in technical education. Over the last century, different theories were born about human hemispheres behaviour and the source of creativity. As the answer is not simple and complex cognitive function are required in engineering, may be is the best to associate creativity with other important concepts as originality, fast shift between rational and visual approaches, learning system development.
\end{abstract}

\section{Introduction}

In 1998 a world organization named "Campaign for Learning" leads a research on the human motivation of developing themselves, stretching their brains and improve the learning capacity. The conclusion is that both adults and young people enjoy learning new things encouraged by their current or possible future jobs rather than to their personal interests [1]. Adults prefer to learn doing practical things or self-study, young people prefer learning in groups.

Learning is an interesting process. In particular, technical education is following the ' 80 trends becoming more and more preoccupied by virtual reality and standardization. Since the beginning of the industrial revolution process, fragmentation increases productivity which is how left hemisphere of our brain imagines the world. This is an entirely and abstract model that has procedures (laws to do so) and defined area (boxes containing people and/or goods).

A better understanding of our brain cognitive functions can help us to become more productive, efficient and creative.

\section{How our brain works}

\subsection{The map of the brain}

Each individual thinks in a different way from another. But there is a common pattern regarding cognitive functions.

Left hemisphere is involved in sequential matters, mathematics and logics, sees details and puts them together to form the bigger picture, handles organization and logic and loves rules and regulations.

\footnotetext{
*Corresponding author: simonaduicu@unitbv.ro
} 
The right part is the root of our emotions, intuition and visualization, sees all the visual references as a whole, works with curiosity and associativity.

Roger Sperry defined in the ' 60 the specific activities of our hemispheres, and since than almost everybody considered the right part, the creative one (figure 1). But thinking further, we may discover that creativity is an attribute of both hemisphere but in different ways.

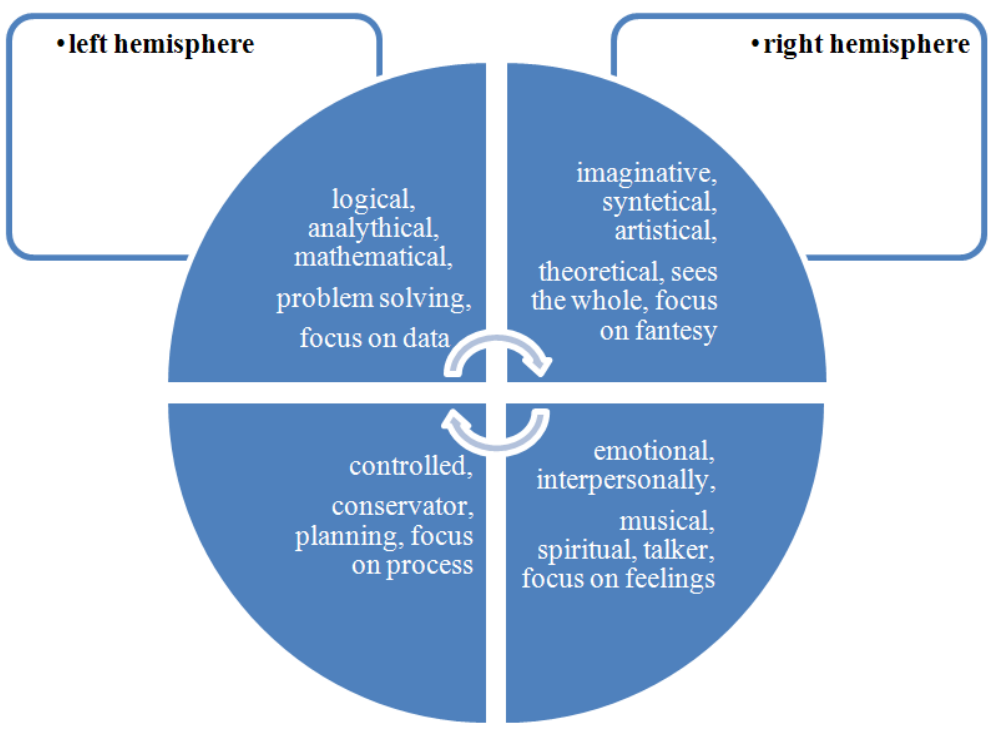

Fig. 1. A brain "map".

All four quadrants contain in a very simplify manner different type of characteristics [2], without ignoring the fact that hemispheres are full time connected by the corpus callosum.

The second important idea is that we are using our intelligent brain to interact with other people or with the surrounding world. When we do so, we are using our left hemisphere by developing the capacity of being able to use words and harmonize ourselves for our benefit. We also use our left hemisphere to imagine gesture, to create language, to nominate tools and to associate experiences with "ideograms" in our brain. And these ideograms are defined with high precision to be used later. This is how our left brain recreates the reality: from small parts to the big puzzle; is like every time we experience something new we add a flag to a map we will use later [3]. The right hemisphere will make all the time the comparison between what we already lived and the current reality. The right part of our brain understands contexts, the meaning of facts, even the body language, emotional expression, metaphors; it understands individuality, makes categories, in working in process.

The right hemisphere doubts, analyses, the left one performs mechanical. Even if on the left part is created the idea of performing an act, in the right one we will find the reason to do it. The profound statement is that reason and imagination don't have their own specific places in different hemisphere.

If we consider the left hemisphere responsible with the creation of the language, than we have to agree about certain mechanisms responsible with this: abstraction, item isolation, static definition, taking out from the context, nomination; the right hemisphere works with all concepts created by the left one, makes connections, understands life, changing and evolution, but creates also other connections between things and processes and relations between living things or humans. And all these lived and analysed 
experiences creates in our right hemisphere new knowledge and paths linking existing items and abilities to use what we know.

Modern society must understand that creativity is important for a sustainable and majestic development. But this can happen only if the logical left hemisphere works in conjunction with the powerful, visual and introspecting right one. This means to step back and come with new fresh idea by cultivating mental flexibility, confidence and patience in alternative problem solving. Both our hemisphere have the ability to create.

\subsection{Where is creativity born?}

Creativity can be defined as the use of imagination to generate original ideas. But where is born the creativity, in the left or in the right hemisphere? Left part of our brain takes everything out from its context if something new appears and creates a new image or a word for this. The right part analyses this new created items in a continuously changing context. So which part is more creative? How can we translate this sentence: "I have a feeling that it will work". Feeling is the attribute of the left hemisphere, but the sense of doing, the meaningful is the right's one. Einstein said that intuitive mind is a sacred gift and the rational one is a faithful servant, and all of this because the world surrounding us is changing. Our brain compares new realities with existing models. When is no model there, there are two paths: one to create a new one from the beginning, and the second, to ask a computer to simulate one for us.

Viewing problems from a new perspective, creativity could be the ability to find alternative solutions to problems or a new approach. Means to cultivate mental flexibility and the desire to face challenges or boredom.

\subsubsection{Barriers against creativity}

There are seven accepted barriers against creativity: school, sarcasm, social pressure, status-quo, standardization, silos and costumes [2]. Table 1 exposes the barriers vs. creativity resources.

Table 1. Barriers against creativity vs. creativity resources exploiting.

\begin{tabular}{|c|c|}
\hline Barriers & Resources to be exploited \\
\hline School & Formulate tests with multiple answers; flexibility in testing methods \\
\hline Sarcasm & Postpone critical judgments during problem solving; brainstorming \\
\hline Social pressure & Avoid social stratification during problem solving \\
\hline Status-quo & Broke status-quo, myths, prejudices \\
\hline Standardization & Rethink the problem from zero level, don't use old thinking patterns \\
\hline Silos & $\begin{array}{c}\text { Create an open culture of the organization, don't keep departments, curricula or } \\
\text { people isolated in closed deposits }\end{array}$ \\
\hline Costumes & Use the outfit to send messages, to express yourselves \\
\hline
\end{tabular}

We may train ourselves to be creative if we will be motivated by this desire. Training creativity for students may implicate mixture of disciplines like descriptive geometry and technical drawing, or geometry and design. I met creative students who can't work and 
studying a schedule, dreamy but not irresponsible, full of quiet energy; they worked with a big passion for their projects without caring about the time; they need to be encouraged, to instill confidence because pride and the sense of achievement is very important to them.

Empathy is also a feature that can be exploited with this kind of people who are, by the way, very objective about their work.

I ask my students at the first seminar to follow my example in solving a problem, than I ask somebody else to take my role by solving and explaining to their colleagues as they were a teacher. Without knowing what they do, they had to play a new role, to break the boundaries between student and teacher, to assume their new status and to rethink the entire process from a completely different position. Students who accepted that challenge had a better understanding of the problem and become more confident in the next sessions. They were able to find new solutions looking from a different angle.

\subsection{Boost creativity by making liaisons}

New ideas are very rare, most of them are creative liaisons between existing or old one. Nicholas Negroponte from MIT said that new ideas come unexpectedly, born from contradiction, from another perspective or from a complex mix of different theories [4]. So, a good exercise is to make unexpected connections between existing ideas, dialog with other people or taking out the problem from the context.

Playing with liaisons is a very simple exercise; here there are some very simple examples about how new idea was born:

- $\quad$ technical drawing + computer $=$ computer aided design CAD;

- mathematics + logics + computer $=$ computer programming;

- long life learning + computer skills = e-learning;

- imaination + new technologies $=$ virtual reality.

A good sketch of this kind of training requires: problem identification, growing the data base of possibilities and serve results. If the first and the last step are easy to settle, data base of possibilities has to provide step by step a clear and obvious solution.
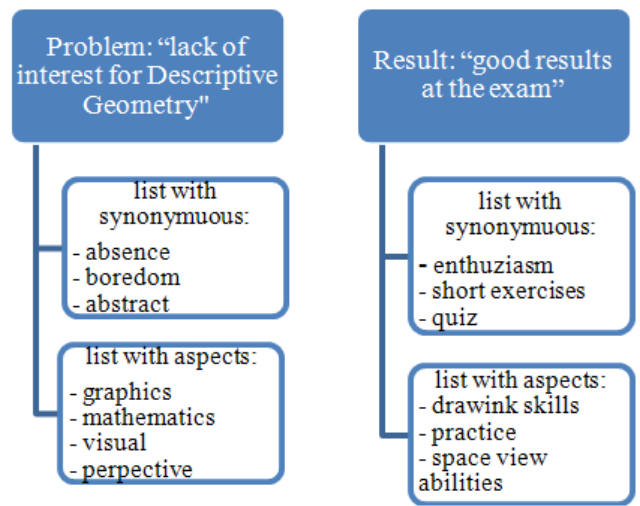

Fig. 2. Methods to enlarge data base.

Some methods to obtain the data base:

- make a list with synonymous for the problem and the result;

- write down as many aspects you find about the problem and the result;

- try to make visual or colour associations between problem and result;

- focus on problem details and result one;

- take short brakes, drink water.

Figure 2 exemplifies the process with only two methods. 


\subsubsection{Playing different roles}

The idea of the playing different roles when a creative solving problem has to be done belongs to Edward de Bono and Bill Lucas [2]; the method is called "creative hats" and associates six colourful hats to six different roles played during problem solving:

- white for data, numbers and information input;

- red for sensations and intuitions;

- black for the moments when we think logical and negative;

- yellow for the moments when we think logical and constructive;

- green when we bring creative idea to move forward;

- blue when we act like a leader to manage all the process successfully.

Splitting a creative team by different roles can be an interesting approach in project management. It can be a way to organize students during lab activities or implement the system for each of them for their homework. This will engage flexibility in taking decisions and also develops lateral thinking which is one of the most important approach in creativity development [5].

Some of the "hats", the red and the green one are working with intuition. This brain capacity is not coming from our evaluated hemispheres but from the inner one, the limbic system responsible with feeling analysis, long term memory and processing information provided by the senses. So, it's nothing to do with learning but with our ability to understand our instincts. These creative energies can be focused to change the personal perception over a certain subject.

A good example how to use this method is a new projection about transportation. Being an automotive engineer I'm all the time concerned about this fast consumed and high technology involved in vehicles. An example regarding how to manage a creative concept is figured in caption 3.
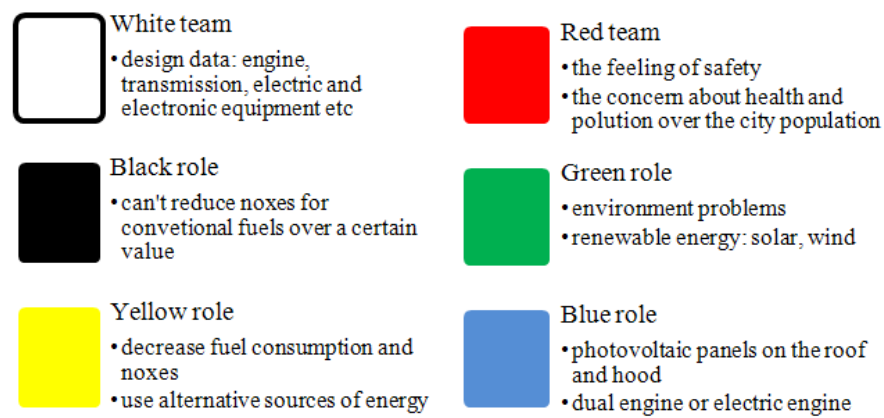

Fig. 3. Managing a creative concept.

The result of this approach can be the creation of a new paint with photovoltaic properties or a photovoltaic network covering the body of the car.

\section{Shift for a new approach}

Howard Gardner proposes a multiple approach of the knowledge [6] and identifies six access ways depending the way of thinking: the narrative way, the quantitative and numerical, the existential or the fundamental, the aesthetical, the practical and the social one. Going deeper in the subject, we may associate these ways with the creative hats or the colourful roles. 
The quantitative and numerical way is the white one. People who access this path are interested developing patterns and procedures type of measurements.

The fundamental and existential way is the black one, suitable for people interested in fundamental, basic questions. They ask themselves about important aspects of life like: who we are and where we came from. They doubt, they are interested in the human capacity, they borrow idea from myths that guide their life.

The practical way is the yellow one, involving experiments, material manipulation, counting, building something, being logical and constructive.

The aesthetical way is green, inspiring equilibrium, harmony, a balance in composition; "green people" have an interior reference.

The social way is blue, connecting people, assuming roles and managing them. People who follow this path are capable to observe other people perspective, to interact with them and to harmonize them.

The red way is the narrative access path suitable for people who learn through stories. Remembering the red role dealing with intuition and sensations, we may understand that this kind of people need stories to imagine conflicts and problems to be solved. They need the dramatic tension to be challenged.

Some attributes of the roles need the left hemisphere, some the right one, but serving the information to each people in a specific mode is a new approach. It is considered that those with dominance in the right brain can be more creative, having a natural creativity; left brained people can be as creative as the others but in a different way [7].

\subsection{Training the pragmatism}

"Learning is the process in which knowledge are created through experience transformation" said David Kolb in 1984 [8]. What is interesting in this approach is the focus on the pragmatism; the training is combining thinking capacities and action (figure 4). This means that we have to train people according to their past experience. This will engage all the time a link with their past, their different stages of education.

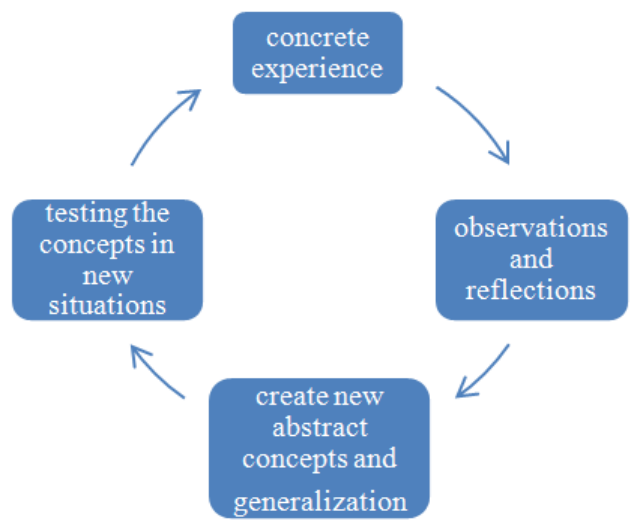

Fig. 4. Learning cycle after Kolb.

This diagram shows how, during a long period of time, education was so focused on individuals that the relation between the subject and the environment is forgotten. Moving the training from the internal mind in the social structure can define a more integrative thinking. 
This pragmatic approach is very often choose in the technical education. We train our students to be practical, but is difficult for us and for them to understand the role of the creativity and innovation. It comes a time when we can't understand the concept of recycling their knowledge. This recycling will renew practice, it will develop the critical thinking and all the idea about action would be connected through language and other communication environments (like computer programming languages etc.) with others. And here emotions and conflicts can appear. Who says that we can be practical and original in the same time? If we go deeper in Kolb's diagram we can't say in which stage we are using our left or right brain more.

\subsection{Training the creativity - an integrative approach}

In figure 5 I adjust the learning cycle after John Heron [9].

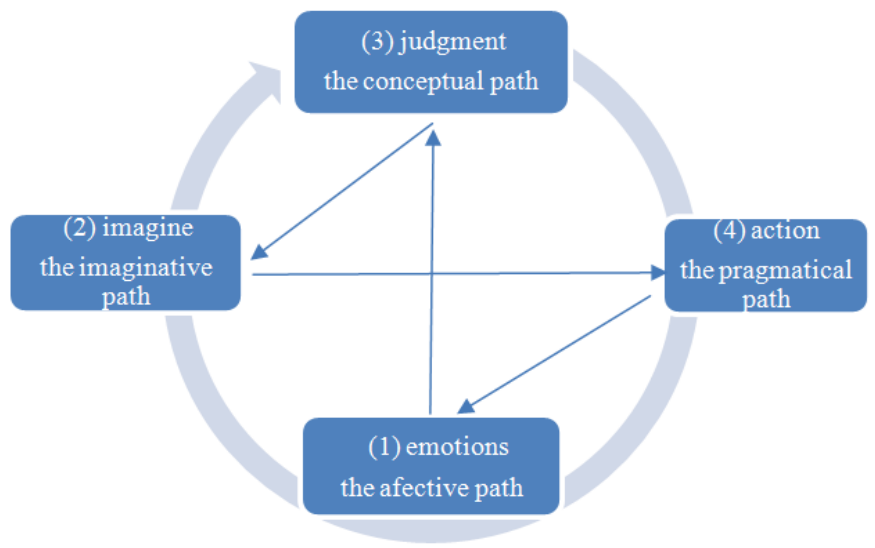

Fig. 5. Reverse learning cycle.

In the first stage, teacher has to establish an emphatic connection with the students, understands his interest and student's needs. This is the world of "presence" of "being". Passing in the second stage, teacher has to ask questions, and talk with students to fill the complete image of their level of education. In this stage teachers or trainers has to explore analogical the situation of the student (he must imagine the training plan comparing the actual picture with one of the existing patterns or curricula). It is more an intuitive perception because there was no previous examination of the student aptitudes. In the third stage teacher has to judge what best educational plan must be applied by making different hypotheses and, in the final, to propose the training plan. This circle is a normal learning circle. If we consider training like a simple already establish knowledge acquisition, than this is only learning. If new bring in this acquisition some new information, this will require research. Than learning plus research means creativity training.

Technical education is using the reverse learning cycle: in the first stage students realize they have no idea or only little information about the subject. It is the emotional stage. If we can exploit this stage by increase enthusiasm but offering in the same time a challenging situation, we may boost the premises of the creativity. This stage is more linked with the third one; students observe and identify themselves their level. In this moment they are using intensively their left hemisphere they work with their existing concepts about the subject trying to imagine (stage three) what is about the subject. This conceptual stage can be experience in a positive state of mind, preparing an open future approach. I think this is the rational stage in which is born the idea of "personal development". Concept evaluation followed by new, alternative idea may compose a complete new model of behaviour. 
Student's attention migrates from frustration and ignorance to the image of a future (stage three). This projection is a right hemisphere responsibility even the roots come from judgment, from the right one. If they could apply something they imagine (stage four), the action can modify the initial state of mind and the emotions from the first stage to be shifted.

So, a new cycle is born. The normal training cycle was exemplified for teachers, the reverse one, was for students.

\section{Conclusion}

The shift for a new creativity education starts with the idea that we are individuals, we can anticipate some of the thinking and acting patterns but we have to provide a multiple faces of the information to develop ourselves. People can improve their originality in every stage of their education:

- train their left and right hemisphere with specific exercises;

- play different roles when a problem has to be solved;

- follow different paths according to their personality;

- modify their way of learning through narrative, experience, images, and practice ways;

- conscious assuming of the learning cycle in every significant aspects of it.

There are no specific tools and resources to access to organize creativity training. There is no specific field in which creativity is less important. Constant improvement of this human attribute can make us more flexible in thinking and more adaptable to change.

\section{References}

1. ERIC number ED 422468, Attitude to learning '98. MORI State of the Nation Survey: Summary report, T.Greany editor (1998), http://eric.ed.gov/?id=ED422468

2. L. Bill, Power up your mind. Learn faster, work smarter. Meteor Publishing, (2016)

3. I. McGilchist, The divided brain \& the making of the western world, RSA Animate, https://www.ted.com/talks/iain_mcgilchrist_the_divided_brain

4. N. Negroponte, Where do new ideas come from, http://www.wired.com/1996/01/negroponte-53

5. S.S. Duicu,About changing paradigms in technical education, 10,13, (2015) http://www.sorging.ro/en/revista/10-special-issue-fascicle-5/

6. H. Gardner Instructional-Design Theories and Models: A new paradigm of instructional theory, in Contemporany Theories of Learning,( Editura trei, 2014)

7. K. Knight, Understanding your brain for better design: left vs. right, http://www.webdesignerdepot.com/2009/11/understanding-your-brain-for-better-designleft-vs-right/

8. D. Kolb, in Contemporany Theories of Learning (Editura trei, 2014)

9. J. Heron, The cycle of life and the cycle of learning in Contemporany Theories of Learning (Editura trei, 2014) 